\title{
Electronic Cigarettes' Toxicity: From Periodontal Disease to Oral Cancer
}

\author{
Alexandra Jităreanu 1, Luminița Agoroaei ${ }^{1,+}{ }^{\text {, }}$, Ovidiu Dumitru Aungurencei ${ }^{2,+}$, Ancuța Goriuc ${ }^{3, *}$, \\ Diana Diaconu Popa ${ }^{4, *}$, Carmen Savin ${ }^{5}$, Ioana-Cezara Caba ${ }^{1}$, Simona Tătărușanu ${ }^{6}$, Bianca Profire ${ }^{7}$ \\ and Ioana Mârțu ${ }^{4}$
}

check for updates

Citation: Jităreanu, A.; Agoroaei, L.; Aungurencei, O.D.; Goriuc, A.; Diaconu Popa, D.; Savin, C.; Caba, I.-C.; Tătărușanu, S.; Profire, B.; Mârțu, I. Electronic Cigarettes' Toxicity: From Periodontal Disease to Oral Cancer. Appl. Sci. 2021, 11, 9742. https://doi.org/10.3390/ app11209742

Academic Editor: Oleh Andrukhov

Received: 30 September 2021

Accepted: 15 October 2021

Published: 19 October 2021

Publisher's Note: MDPI stays neutral with regard to jurisdictional claims in published maps and institutional affiliations.

Copyright: (c) 2021 by the authors. Licensee MDPI, Basel, Switzerland. This article is an open access article distributed under the terms and conditions of the Creative Commons Attribution (CC BY) license (https:// creativecommons.org/licenses/by/ $4.0 /)$
1 Department of Toxicology, Faculty of Pharmacy, University of Medicine and Pharmacy "Grigore T. Popa", 700115 Iași, Romania; jitareanu.alexandra@umfiasi.ro (A.J.); luminita.agoroaei@umfiasi.ro (L.A.); ioana-cezara.caba@umfiasi.ro (I.-C.C.)

2 Department of Odontology-Periodontology, Faculty of Dental Medicine, University of Medicine and Pharmacy “Grigore T. Popa”, 700115 Iași, Romania; ovidiu.aungurencei@umfiasi.ro

3 Department of Biochemistry, Faculty of Dental Medicine, University of Medicine and Pharmacy “Grigore T. Popa", 700115 Iași, Romania

4 Department of Dental Technology, Faculty of Dental Medicine, University of Medicine and Pharmacy "Grigore T. Popa", 700115 Iași, Romania; ioana.martu@umfiasi.ro

5 Department of Pediatric Dentistry, Faculty of Dental Medicine, University of Medicine and Pharmacy "Grigore T. Popa", 700115 Iași, Romania; carmen.savin@umfiasi.ro

6 Department of Pharmaceutical Chemistry, Faculty of Pharmacy, University of Medicine and Pharmacy "Grigore T. Popa", 700115 Iași, Romania; simona-maria.v.rotariu@d.umfiasi.ro

7 Department of Internal Medicine, Faculty of Medicine, University of Medicine and Pharmacy "Grigore T. Popa", 700115 Iași, Romania; bianca-stefania.m.profire@students.umfiasi.ro

* Correspondence: ancuta.goriuc@umfiasi.ro (A.G.); antonela.diaconu@umfiasi.ro (D.D.P.)

$\dagger$ Authors with equal contribution as the first author.

Abstract: Electronic nicotine delivery systems first appeared on the market in 2003 and have been promoted as healthier alternatives to conventional tobacco cigarettes. The rapid evolution of technology for these products generated a wide variety of models, and electronic cigarettes have quickly gained worldwide popularity. However, research regarding the effects of both short-term and long-term exposure revealed a wide variety of potential negative effects on human health, and the first system to be affected by these electronic smoking devices is the oral cavity. This review makes an up-to-date extensive presentation of the possible mechanisms that associate electronic cigarette smoking with increased prevalence and progression of oral cancer. Oxidative stress, inflammation response, and DNA damage are the main mechanisms that explain e-cigarettes' cytotoxicity, but there are still questions to be answered. At present, tens of thousands of e-liquids are available, with distinct compositions, which makes the research even more challenging. Another aspect approached in the present paper is the effect of nicotine on chemotherapy drug resistance. Nicotine activates nicotinic acetylcholine receptors, consecutively inhibiting apoptosis, increasing tumor cells proliferation and survival, and reducing the effects of chemotherapy drugs.

Keywords: chemoresistance; e-cigarette; mechanism; nicotine; oral cancer

\section{Introduction}

Electronic nicotine delivery systems have been on the market for almost two decades. In a short period, they became very popular, because their marketing strategies emphasized the ideas of safety and harm reduction in comparison to traditional tobacco products. Today, there is extensive evidence of potential health concerns of vaping [1].

Electronic cigarettes are battery-operated and they consist of a metal heating element, a cartridge, an atomizer, and a battery. The heating mechanism vaporizes the e-liquid, and the formed vapors are inhaled by the user. The used e-liquids are glycerol/propylene glycol-based solutions that contain nicotine and flavorings [2]. 
The evaluation of the toxicological profile of e-liquids and e-vapors is quite difficult because of the lack of knowledge about their chemical composition, and exposure also depends on the device's characteristics, such as voltage and temperature [3].

The focus of this review is on the impact of electronic cigarette use on oral health because the oral cavity is the first and one of the most affected systems in the human body. There are many unknown aspects related to the long-term effects of e-cigarettes on the oral cavity, and a better understanding of these effects can increase awareness in the general population, but also help specialists in the monitoring and treatment of dental patients. This subject is of great interest because vaping is becoming a major public health problem worldwide, especially among young people, and the safety of smoking electronic devices is questionable.

The literature search for the present study was conducted in PubMed and Web of Science.

\section{Effects of Electronic Cigarettes on the Oral Cavity}

The oral cavity, the first system in the human body in direct contact with the vapors produced by electronic cigarettes, is very exposed to the negative effects of vaping (Figure 1). The evidence of a direct link between e-cigarettes smoking and oral diseases (periodontal disease and oral cancer) is not easily obtained, because these harmful effects can be assessed after a long period of exposure, and chronic diseases (like periodontitis and cancer) need several years until the clinical symptoms appear [1].

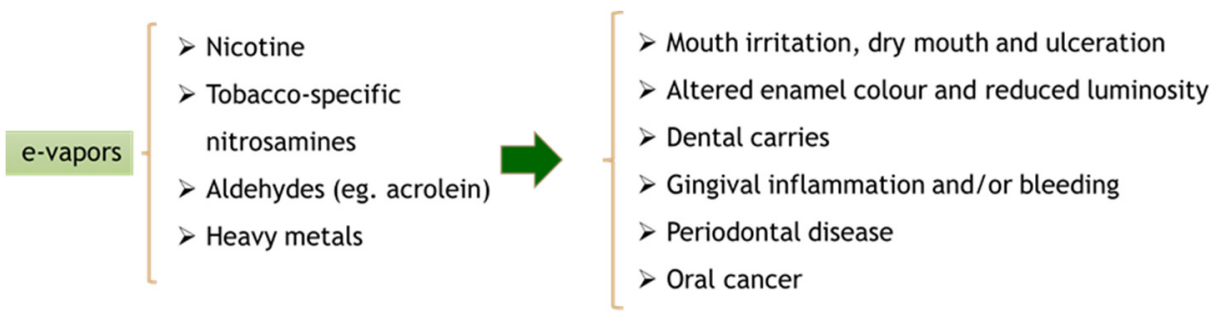

Figure 1. Effects of electronic cigarettes on oral cavity.

There are a few clinical studies addressing the direct impact of vaping on the oral cavity [4]. In one cross-sectional analysis performed by Huilgol et al., a link between poor oral health, increased odds of permanent tooth loss and daily use of e-cigarettes was observed [5]. Additionally, electronic cigarette users reported adverse events like dry mouth, sensitive teeth, mouth ulcers [6]. Another study that is often cited as evidence for the harmful effects of vaping refers to the increase in gingival bleeding that appeared when a group of smokers switched to e-cigarettes [7].

When it comes to evaluating clinical (plaque index, bleeding on probing, probing pocket depth, clinical attachment loss) and radiographic parameters of periodontal inflammation, the evidence suggested that the risks of developing periodontal disease were lower in e-cigarette users in comparison with conventional tobacco smokers, but higher than for non-smokers [8-10].

With regard to subjectively evaluating the clinical effects of electronic cigarettes on oral health, there are a few aspects that make this task challenging. One of the most important is related to the period required by several chronic diseases to develop, as mentioned above, while the popularity of these devices started to grow only within 5 to 10 years. To have a clear image, decades might be necessary until extended epidemiological studies could precisely estimate the impact of electronic cigarettes. Furthermore, many electronic cigarette users are former conventional tobacco smokers or dual users, therefore it is difficult to distinguish between the effects of traditional and electronic cigarettes [4].

Cancer represents a leading cause of death, and its incidence and mortality are rapidly escalating worldwide. In 2020, 377,713 new cases of oral cancer were recorded globally (according to GLOBOCAN). Several of the risk factors for cancer are associated with 
socioeconomic development and with human behavior, and epidemiological studies have reported that smoking is a major etiological factor for oral cancer [11,12].

Oral squamous cell carcinoma (OSCC) combines several cellular and biochemical alterations, accompanied by clinical modifications, affecting the morphology and function of the epithelium of the oral mucosa. Sometimes, this is preceded by white, red, or mixed mucosal changes, known as oral potentially malignant disorders (OPMDs). In the category of OPMDs are included oral lichen planus (OLP), leukoplakia (LPK), and oral submucous fibrosis (OSF). The malignant transformation rate for OLP was $1.1-1.63 \%, 0.13-17.9 \%$ for LPK, and $7.6 \%$ for OSF. Habitual usage of different types of tobacco products (including smokeless tobacco) is associated with a higher risk of oral potentially malignant disorders and is an important etiological factor for oral cancer [13].

Periodontal disease affects the supporting tissues of the teeth and is characterized by chronic inflammation status. There is a potential link between periodontal disease and oral cancer, and one mechanism that can explain this connection is particularly the chronic inflammation status associated with periodontal disease, which can affect normal cell growth control and induce carcinogenesis. Some studies confirm a relationship between periodontal disease and oral cancer [14,15].

Numerous microbial species colonize the oral cavity and form the oral microbiome. It is a well-known fact that cigarette smoking is a major factor for the alteration of the eubiotic balance, and there is also evidence that vaping can affect the profile of the oral microbiome, although the studies on this issue are still scarce. Dysbiosis can be characterized by the alteration of microbial diversity, with the loss of beneficial microorganisms, and excessive proliferation of the pathogenic microbes. This unbalance can reduce the host's ability to fight pathogens and increase the susceptibility to infections, and to carcinogenic compounds $[4,16,17]$. In consequence, dysbiosis is associated with the initiation and progression of various oral diseases (dental caries, halitosis, periodontitis, and oral cancer) $[16,18]$.

Tissue damage, as a result of vaping, cannot only affect the integrity of gingival tissue but can also potentiate inflammatory responses, as well as setting up an optimal environment for bacterial growth. Pushalkar et al. investigated the effects of electronic cigarette aerosols on the human salivary microbiome and found that e-vapors exposure was linked to a higher abundance of periodontal pathogens. The proliferation of Veillonella and Porphyromonas was significantly higher in e-cigarette users, in comparison with conventional smokers and nonsmokers, and it was accompanied by high levels of proinflammatory cytokines [19].

Ganesan et al. revealed that the changes that appeared in the microbiome and the differences in bacterial biofilm production and architecture are more likely to be caused by the glycerol and propylene glycol present in e-liquids and not by nicotine. These sugar alcohols can become a source of nutrients for bacteria. They also discovered high virulence signatures, and proinflammatory signals in clinically healthy e-cigarette users, and they emphasize the fact that pathogenetic mechanisms associated with e-cigarette use might be different from conventional cigarettes [20].

Oral microbiome alterations can be linked to the appearance of periodontitis and even oral cancer. Periodontal pathogens (S. anginosus, C. gingivalis, P. melaninogenica, $F$. nucleatum) determine an increase in markers of systemic inflammation including $C$-reactive protein, interleukin (IL)-1, IL-6, TNF-alpha, and MMPs, which may lead to carcinogenesis [21,22]. P. gingivalis, T. denticola, and F. nucleatum promoted oral cancer migration and aggressivity. Therefore, the concepts of periodontal pathogen-mediated carcinogenesis, as well as antimicrobial-based cancer therapy have emerged [16-18].

Furthermore, due to the direct interaction with the carcinogens from cigarette smoke and e-vapors, and to the fact that oral epithelium possesses xenobiotic enzymes capable of converting proximate carcinogens to reactive metabolites, this tissue becomes a major target for smoking/vaping-associated cancer [23]. 
Oral cancer susceptibility is modulated by environmental factors and genetic alterations in oncogenes and tumor suppressor genes [24], and the mechanisms involved in the prevalence and progression of oral cancer are complex. A better understanding of this process can help scientists develop targeted therapies, maximize the efficiency of current drugs, but it can also have an impact on increasing awareness in the general population, thus reducing exposure to potential risk factors.

\section{Potential Mechanisms Involved in Oral Cancer Development Associated with Electronic Cigarette Smoking}

Usually, different forms of cancers share an etiology of oxidative stress associated with inflammation, DNA damage, and disrupted immune processes. Accumulation of mutations in genes encoding homeostatic regulators of DNA mismatch-repair factors, predominantly in stem cells becoming CSCs (cancer stem cells) is the leading event in carcinogenesis. The immune system and inflammatory reactions are activated when pathogens or other nonself-molecules enter an organism. Their role is to eliminate the threat agent or to control systemic colonization, but the same physiological responses induce repair mechanisms that recover the function and integrity of tissues in an organ with a tumor [25]. In carcinogenesis, a shift from anti-inflammatory to pro-inflammatory pathways is observed, and excessive production of inflammatory agents and cytotoxic mediators (like reactive oxygen species) promotes genomic instability and neoplastic development. Under these circumstances, the immune system can no longer maintain cell and tissue homeostasis (Figure 2) [26].



Figure 2. The process of carcinogenesis.

There are several potential mechanisms that associate electronic cigarette smoking with increased prevalence and progression of oral cancer.

\subsection{Oxidative Stress}

Oxidative stress occurs as a state of disturbance between free radical production and the capability of the body's antioxidant system to counteract them. Free radicals are classified as reactive oxygen species (ROS) or reactive nitrogen species (RNS), and both possess unpaired valence electrons, which make them highly reactive. The salivary antioxidant system is one of the most critical defense mechanisms, and it consists of enzymes (peroxidase, catalase, superoxide dismutase, glutathione peroxidase) and other compounds, like glutathione, and vitamins E and C [26-28]. Glutathione is one of the most important antioxidant agents, vital for protecting cells against oxygen reactive species, but also against the reactive aldehydes found in e-vapors. The thiol group of the glutathione molecule reacts with the electrophilic aldehydes and forms GSH-aldehydes adducts (mainly GSH-acrolein and GSH-crotonaldehyde) [29]. When the natural defense systems are overwhelmed, structural alterations and DNA damage can appear. The most abundant oxidative DNA lesions are considered to be 8-oxo-7,8-dihydro- $2^{\prime}$-deoxyguanosine (8-oxo-dG), and exposure to e-vapors is linked to a higher frequency of 8-oxo-dG. Chronic oxidative stress can also cause impaired BER (base excision repair) activity, which reduces the efficiency of DNA repair [26-28].

There is scientific evidence that smoking minimizes the antioxidants activity. Several studies indicated that the reactivity of oxidants/reactive oxygen species found in 
e-cigarette aerosols is comparable to the one in conventional cigarette smoke $\left(7 \times 10^{11}\right.$ free radicals/puff for e-cigarette vapors compared to $10^{14}$ in cigarette smoke), and that chronic exposure can cause systemic oxidant-antioxidant imbalance [26,29-31]. The components from e-cigarette aerosols have the ability to disturb the function of the mitochondrial respiratory chain complexes, and mitochondrial malfunction is a key element in acute and chronic cellular stress [32]. Furthermore, the reorganization of the extracellular matrix and the disruption of collagen biosynthesis can be triggered by prolonged inflammation and oxidative stress [27]. Oxidative stress also increased the expression of pro-apoptotic proteins, with a more pronounced effect seen for nicotine-containing e-liquids (Figure 3) [33].

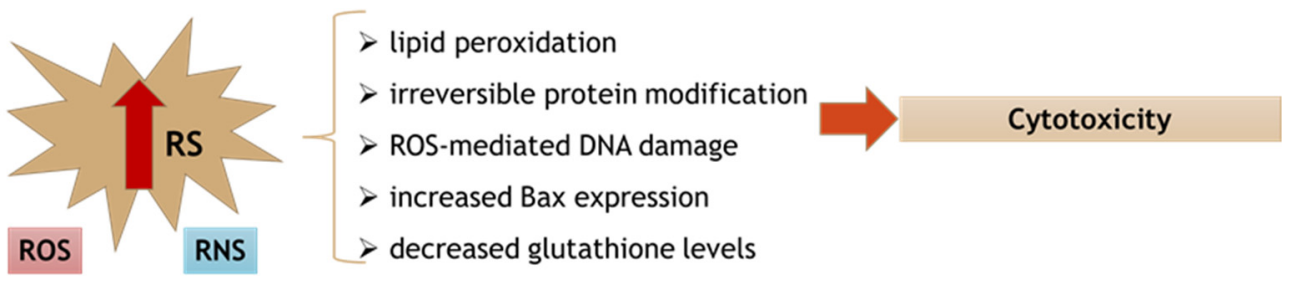

Figure 3. Oxidative stress implications.

\subsection{Inflammatory Response}

The concept of inflammation-associated tumorigenesis has attracted the interest of several research teams in recent years. A complex inflammatory cascade and a high production of cytokines can be linked to several oral cavity diseases, from periodontal disease to oral cancer. Cytokines are important regulators of the immune processes, involved in inducing growth, proliferation, and differentiation of normal cells, in inflammation and tumorigenesis. Increased inflammatory reactions can lead to the alteration of the mucosal epithelium, which can respond to external aggression through morphological adaptations (keratinization, metaplasia) [34]. The cytokines that are most commonly assessed in saliva are IL-6, IL-8, IL-1 $\beta$, and TNF- $\alpha$. Their salivary levels are also linked to predicting the prognosis and progression of precancerous lesions [34]. High IL-8 levels may promote carcinogenesis due to its ability to induce cell proliferation and promote DNA damage, but also by upregulating gene transcription and activity of metalloproteinase-2. By stimulating the activity of collagenases, IL8 is also associated with metastasis and enhanced tumor cells invasion in healthy tissues [24].

In inducing oncogenic inflammatory conditions, STAT3 signaling is a major intrinsic pathway, involved in the initiation and progression of malignant transformation. It is frequently activated in cancer cells and capable of inducing a large number of genes encoding for inflammation. STAT3 hyperactivation may be due to two molecular events, one is constitutive activation by cytokine stimulation and the other is loss of SOCS (suppressor of cytokine signaling) proteins expression [35].

To better understand the effect of electronic cigarettes on oral tissues, Sundar et al. showed that exposure to e-vapors with flavorings caused increased carbonyl stress and inflammatory cytokine release in human periodontal ligament fibroblasts, human gingival epithelium progenitors pooled, and epi-gingival 3D epithelium. Increased levels of prostaglandin-E2, cyclooxygenase-2, and IL-8 were observed [2].

TNF- $\alpha$ is another promoter in the process of carcinogenesis, and Faridoun analyzed in a pilot study the salivary levels of TNF- $\alpha$ in the group of electronic cigarette smokers were significantly higher than in the control group, despite the lack of tobacco combustion [34].

To gain insights into the mechanism by which smoking could affect oral cancer cells, and tumor invasion and metastasis, Allam et al. examined the collagen degrading ability and MMP (matrix metalloproteinase) production of two lines of oral carcinoma cells (metastatic and non-metastatic) exposed to cigarette smoke condensate. There is clear evidence of the connection between tumor progression and metastases and the expression and activity of MMP-2 and MMP-9 because one of the key elements in the metastatic cascade is the degradation of collagen, which disrupts the extracellular matrix 
and basement membranes. The conclusion of the study was that continued smoking in oral cancer patients can enhance the metastatic potential of cancer cells, reducing the survival rates [12].

\subsection{DNA Damage and Genotoxic Mechanism}

Genotoxicity and DNA damage are linked to the malignant transformation of normal cells. Alanazi et al. demonstrated that electronic cigarettes affect periodontal tissue by inhibiting the proliferation of human gingival fibroblasts through apoptotic mechanisms. Cell proliferation is a key process for tissue repair. Cell apoptosis was investigated by DNA fragmentation using the TUNEL assay. Exposure to e-vapor condensate also led to altered fibroblasts' morphology. These effects were also visible for nicotine-free e-liquids, pointing to the conclusion that other compounds, besides nicotine, present a toxic potential to the cells [36].

Willershausen et al. also studied the viability and proliferation of human periodontal fibroblasts exposed to e-liquids, and they observed that the highest reduction in the proliferation rate was observed for menthol flavored liquids, pointing to the cytotoxic potential of some additives [37]. In another study, Yu et al. conclusively linked e-cigarettes to DNA breakage, regardless of nicotine concentration. The accumulation of double-strand breaks is suggestive of the carcinogenic potential of e-cigarettes. Increased rates of G1 and G2 arrest were observed among exposed cells, reducing the intervention of homologous recombination, a higher-fidelity double-strand breaks repair mechanism primarily active in the $S$ phase [38].

One assay used for the noninvasive assessment of chromosomal instability, genomic damage, and oral cell death is the buccal micronucleus cytome assay, indicating an elevated risk of carcinogenesis. Micronuclei, extra-nuclear structures produced during cell division containing chromosomes fragments, are important for chromosomal aberrations biomonitoring, both structural or numerical, while binucleation is related to defects in cytokinesis [39].

Different studies demonstrated the genotoxic potential of nicotine. Nicotine-induced micronuclei formation in human gingival fibroblasts and in human primary parotid gland cells. A higher frequency of micronuclei can be associated with a higher risk of cancer $[40,41]$. However, in a cytological study that assessed the prevalence of micronuclei in oral cavity cells, there were no significant alterations in the micronuclei distribution in e-cigarette users in comparison to nonsmokers [33].

Nicotine exposed cells presented increased comet tail length and $\gamma-\mathrm{H} 2 \mathrm{AX}$ foci, signs of increased DNA strand breaks [2]. Nicotine can induce the over-expression of human telomerase reverse transcriptase mRNA in oral keratinocytes, which may play a role in the progression and malignancy of oral submucous fibrosis. This aspect is important because approximately $7-13 \%$ of patients with oral submucous fibrosis will eventually progress to oral squamous cell carcinoma [42].

Deregulations of the cell cycle are considered a fundamental hallmark of cancer progression. In oral carcinoma, several deregulations in cell cycle regulatory protein are frequently seen, and they stimulate carcinogenesis. The abrogation of cell cycle regulatory proteins such as retinoblastoma tumor suppressor protein ( $\mathrm{pRB}$ ), cyclin D1, cyclindependent kinase (CDKs), and CDK inhibitors (p12WAF1/CIP1, p27KIP1, and p16INK4a) occurs in response to stress (both extracellular and intracellular) and DNA damage [13].

When the regulation of genes and associated molecular pathways involved in crucial cellular functions (growth control and differentiation) were analyzed using RNAsequencing, a significant number of aberrantly expressed transcripts were identified in e-cigarette smokers. The Wnt $/ \mathrm{Ca}^{+}$pathway and the Rho family GTPases signaling pathway were the most affected. In e-cigarette users the activators of the Wnt $/ \mathrm{Ca}^{+}$signaling pathway (the tumor suppressor WNT5A gene and the frizzled receptor FDZ7 gene) were down-regulated, this causing the inhibition of downstream effectors of the cascade. The GTPase family regulates a wide range of biological processes (reorganization of the actin 
cytoskeleton, transcriptional regulation, vesicle trafficking, morphogenesis, neutrophil activation, phagocytosis, mitogenesis, apoptosis, tumorigenesis). Rho GTPases may play an important role in the DNA damage response following genotoxin treatment, and these GTPases regulate structures of the nuclear cytoskeleton, assuring the temporal and spatial distribution of DNA repair factors at the site of damage [23,33].

The presence of aldehydes in e-vapors can also explain the delay or inhibition in DNA repair. Acrolein inhibits nucleotide excision repair, base excision repair, and mismatch repair, and it reduces the unscheduled DNA synthesis that usually occurs after DNA damage [43].

Sundar et al. showed that e-cigarette aerosols exposure produces in gingival epithelium persistent DNA damage via RAGE-HDAC2-dependent mechanisms [2].

\subsection{Genetic and Epigenetic Alterations}

The transition from a normal cell to a cancer cell is a multistep process and is usually based on the accumulation of genetic alterations. Cancer progression appears when the alterations occur for the genes that regulate cell proliferation and apoptosis, but also angiogenesis and metastasis. Gene function can be altered in different ways: oncogenes can be activated by mutation or amplification and tumor suppressor genes may be inactivated by mutation, deletion, or methylation. In oral cancer, there are some genetic alterations found with a high frequency: the inactivation of TP53 (located at 17p13), the gain of chromosomal material at 3q26, and 11q13, and losses at 3p21, 13q21, and 14q32. In many cases, the tumor suppressor genes or oncogenes still need to be identified. Alterations like allelic losses at $3 p, 9 q$, and $17 p$ were observed in dysplastic lesions and were associated with early markers of carcinogenesis. However, early genetic changes are not necessarily correlated with altered morphology [44].

The initiation and evolution of oral cancer represent a cascade of complex processes, where both coding and non-coding genes are involved. Therefore, the identification of clinically relevant Oral Squamous Cell Carcinoma (OSCC)-specific circRNAs (circular RNAs) and the examination of their function and regulatory effects on OSCC are crucial to understanding the disease. circRNAs can regulate several cancer-associated pathways, and ultimately the malignancy of tumor cells. Understanding these processes can be used for the design of more effective anticancer therapies for patients with OSCC, increasing survival [45].

circRNA expression levels were compared in OSCC and healthy oral mucosa tissues using high-throughput, next-generation RNA sequencing technology, and a circRNA derived from the gene encoding pleckstrin homology domain-interacting protein (circPHIP) was characterized. Su et al. revealed that circPHIP acts as a ceRNA (competitive endogenous RNAs), regulating OSCC cells by adsorbing microRNA miR-142-5p, which not only displayed strong binding to circPHIP in oral cancer cell lines (SCC15 and CAL27) but also played an important role in the progression and metastasis of oral squamous cell carcinoma. The study indicated that circPHIP is highly expressed in both OSCC tissues and cell lines, and it can act as an oncogene in OSCC, due to its involvement in upregulating the expression of PHIP and alpha-actinin 4 (ACTN4), which are driver genes in OSCC development. circPHIP regulated PHIP expression and, in consequence, affected the malignant behavior of OSCC. Moreover, the overexpression of PHIP and ACTN4 is associated with the activation of PI3K/AKT/mTOR signaling. The circPHIP/miR-142-5p/PHIP-ACTN4 axis can be at the basis of developing new strategies for targeted therapies for OSCC [46].

The term epigenetics refers to the analysis of changes in gene function that are mitotically and/or meiotically heritable and that do not involve a modification in DNA sequence. These modifications directly affect gene expression. MicroRNAs (miRNAs) are small RNA molecules that have the ability to regulate gene expression after transcription, by either inhibiting mRNA translation or by degrading mRNA. These molecules intervene in many cellular, physiological, developmental, and pathological processes, including cancer initiation, progression, apoptosis, invasion, and metastasis. It is appreciated that about $50 \%$ of 
human genes are regulated by miRNAs. Dysregulations of microRNA have been reported in many types of cancers, including oral cancer. They play an important role in human natural killer cell function, epithelial-mesenchymal transition, and suppression of cell migration and invasion in cancer [34,47].

Solleti et al. identified 578 miRNAs dysregulated by e-cigarette exposure (nonvaporized liquids) in human lung epithelial cells, and 125 miRNA affected by vaporized e-cigarette liquids. The data collected during the study showed that e-liquids with nicotine exhibited a greater influence on miRNA expression [48]. Sewer et al. performed a metaanalysis and identified several key miRNAs (e.g., miR-125b-5p, miR-132-3p, miR-99a-5p, and miR-146a-5p) that could potentially serve as biomarkers of response to nicotinecontaining products exposure in human aerodigestive epithelial tissues. Their analysis also revealed that e-vapor products produce smaller changes in miRNA expression than exposure to conventional cigarette smoke [49]. The microRNAs profile of plasma exosomes showed both similarities and differences between cigarette smokers and electronic cigarette users. This is understandable because there are both similarities (eq. nicotine) and differences (eq. combustion byproducts) between cigarette smoke and e-vapors. Singh et al. identified 17 microRNA dysregulated significantly in comparison to nonsmokers, and 24 significant microRNAs between cigarette smokers and nonsmokers. The differences between the epigenetic alterations associated with smoking and the ones associated with vaping were represented by 9 microRNAs (hsa-miR-365a-3p, hsa-miR-1299, hsa-miR-532-5p, hsa-miR-30e-5p, hsa-miR-2355-5p, hsa-miR-362-5p, hsa-miR-193b-3p, hsa-miR-186-5p, hsa$\mathrm{miR}-144-5 \mathrm{p}$ ) that were altered significantly in electronic-cigarette users versus conventional cigarette smokers, when they analyzed plasma exosomes [47].

At present, there are still questions unanswered regarding the implication of these epigenetic biomarkers in the etiology of vaping-associated diseases, in evaluating the relative risks of vaping compared to smoking, and to what extent these epigenetic changes are influenced by the differences in the chemical composition of e-liquids, especially the addition of flavor agents [50].

\section{Chemical Composition of e-Liquids and Vapors and the Implications in Oral Carcinogenesis}

Electronic cigarettes functioning involves heating a mixture of propylene glycol, glycerol, nicotine, and different flavoring agents to produce vapors that are inhaled. All these ingredients potentially contribute to adverse oral health outcomes. Although the e-liquids used for electronic cigarettes have a simple composition in comparison with traditional tobacco products, e-cigarettes were found to be a source of toxic and potentially carcinogenic tobacco-specific nitrosamines, tobacco alkaloids, and nicotine decomposition products, aromatic amines, heavy metals, and carbonyl compounds (Figure 4) [51].
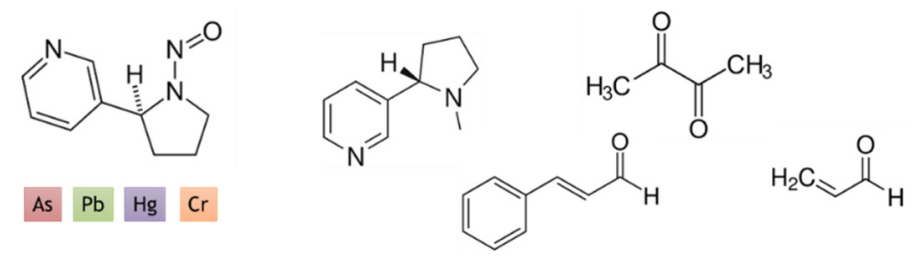

Figure 4. Carcinogens found in e-cigarettes' liquids and vapors.

\subsection{Nicotine}

Nicotine remains one of the main components responsible for the toxicity of electronic cigarettes. Nicotine represents a significant source of concern, because $45 \%$ of the nicotine released from e-cigarettes is deposited in the oral cavity, and its concentrations in saliva are 10.5 times higher than those in plasma [1]. Nicotine can be found in the saliva of all tobacco products users, and its absorption is closely connected to the salivary $\mathrm{pH}$. More alkaline saliva determines higher rates of nicotine absorption [41]. 
E-liquids with nicotine demonstrated a higher degree of cytotoxicity in comparison to nicotine-free samples. In one study, human gingival fibroblasts exposed to nicotine presented vacuolization of cytoplasm, the endoplasmic reticulum was heavily dilated, and the mitochondria were also affected. These changes in the morphology of the cells are considered a sign of lysosome metabolism alteration, impairing the digestive capacity. Nicotine is a lysosomotropic amine, that accumulates into lysosomes, and it raises the $\mathrm{pH}$ above the optimum level for hydrolases activity. By affecting intracellular autophagy, nicotine alters the cell's capacity to degrade dysfunctional and unnecessary components, a skill that is essential for cell survival [52].

There is evidence that nicotine may directly promote carcinogenesis by stimulating lesion development, angiogenesis, and by inhibiting apoptosis [53,54].

Nicotine is metabolized into cotinine and nitrosamines. Nitrosamines are compounds that lead to the appearance of methylation intermediates in DNA. Nicotine and NNK (nicotine-derived nitrosamine ketone) also activate serine/threonine kinase Akt, a member of the oncogene families involved in tumorigenesis. Alterations in Akt activity modify vital cellular processes (glucose metabolism and protein synthesis, cell growth, cell survival and apoptosis, cell migration, angiogenesis), and cause major cellular perturbations, ultimately leading to cancer $[26,55]$.

Nicotine interacts with nicotinic acetylcholine receptors $(\mathrm{nAChR})$ that are found in the central nervous system, but also in non-neuronal cells, where they regulate cellular growth, differentiation, and migration. Nicotinic acetylcholine receptors (nAchRs) are involved in accelerated cell proliferation, tumor invasion, and angiogenesis. Nicotine and tobaccospecific nitrosamines (NNK, NNN) are nAchRs agonists with a high affinity. Nicotine alters the expression levels and the sensitivity of these receptors, which play an important role in carcinogenesis. The activation of these receptors activates proliferative signaling pathways in cancer cells (eq. PI3K/AKT, Raf/MEKK/ERK1/2, NF-KB), which inhibits cell apoptosis and elevates the risk of cancer. Chronic nicotine and tobacco-specific nitrosamine exposure also activates STAT3, which is associated with perturbations in the cell cycle, and chemoresistance [56,57]. Cytokine-inducible $\mathrm{SH} 2$ containing protein (CISH) is a member of the suppressors of cytokine signaling (SOCS) proteins and it regulates STAT3 activity. Peng et al. demonstrated that STAT3 can be activated through a miR-944-mediated CISH down-expression pattern. The results of their study clearly showed that NNK-induced TP63/miR-944 co-expression is an important factor in oral carcinogenesis [35].

The proliferative effects of nAchRs activated by nicotine and NNK were first reported for lung cancer cell lines, but these effects were observed in various normal and cancerous cells. nAchRs are also found on extraneuronal cells, including oral epithelium and oral keratinocytes, where the expressed subunits are $\alpha 3, \alpha 5, \alpha 7, \alpha 9$, and $\beta 2$. In the cells, nAchRs are located at two levels: on the cell membrane and the mitochondrial membrane [57]. $\alpha 7$ is the main subunit that mediates the proliferative effects of nicotine and the development of $\alpha 7 \mathrm{nAchR}$ antagonists can become a target for cancer therapy, but also for enhancing the therapeutic effect of anticancer drugs, nicotine exposure reducing apoptosis in cancer cells treated with different chemotherapy agents [57-60].

Nicotine's implication in cancer development can be also explained by the stimulating effect this compound has on both growth factors, and growth factors receptors (Figure 5) [59]. 


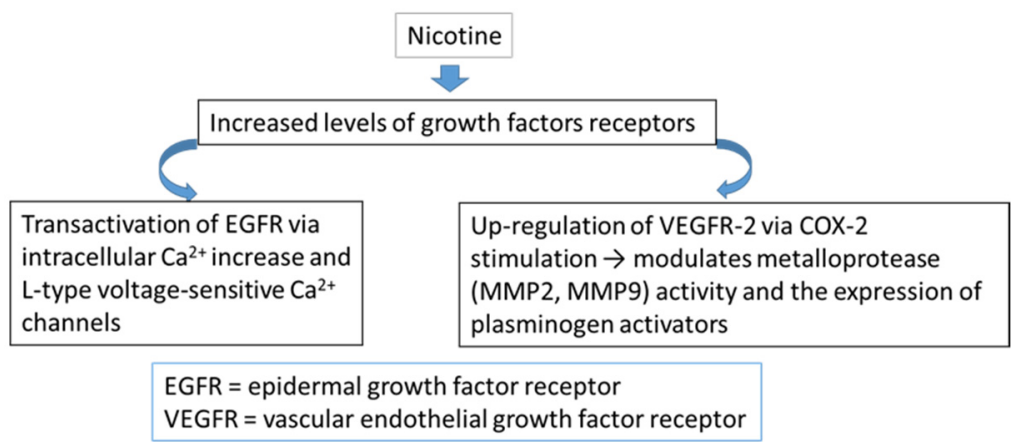

Figure 5. Effects of nicotine on growth factors receptors.

Nicotine has an important role in FASN (fatty acid synthase)/EGFR (epidermal growth factor receptor) signaling; it activates the EGFR signaling through a marked increase in fatty acid synthase expression. This is a pro-oncogenic event relevant to oral carcinogenesis, and EGFR overexpression is associated with increased migration of premalignant cells [26,61].

Nicotine is also involved in epithelial-to-mesenchymal transition; it affects the morphology of oral cancer cells, which acquire migratory abilities associated with metastasis $[62,63]$.

\subsection{Propylene Glycol and Glycerol}

The heating of propylene glycol and glycerol produces acrolein, and $\alpha, \beta$-unsaturated aldehydes, with a proven genotoxic potential in vivo, that forms exocyclic $1, \mathrm{~N}^{2}$ propanodeoxyguanosine adducts with $2^{\prime}$-deoxyguanosine by Michael addition. $\alpha, \beta-$ unsaturated aldehydes do not require metabolic activation and can interact directly to form DNA adduct, even after inhalation exposure. Furthermore, the major pathway of metabolism for acrolein is conjugation with glutathione (GSH). This partially explains why exposure to e-vapors decreases the glutathione (GSH) levels, the major intracellular antioxidant defense within the cells, leading to oxidative stress [43].

Bitzer et al. found that free radical generation is closely linked to the concentration of propylene glycol from e-liquids [64].

\subsection{Flavoring Agents}

The number of e-cigarette brands and flavored products is impressive (over 8000 different flavorings). Many flavoring ingredients are labeled as "generally recognized as safe" (by the Flavors Extracts Manufacturers Association), but their evaluation was performed on food products (at ingestion), and not for inhalation toxicity. Despite the banning of certain flavors from conventional cigarettes, these flavors are still used in all the other products, including e-liquids. Kaur et al. make an extensive presentation of the main e-cigarette flavorings (Table 1 ) and their toxic potential $[65,66]$.

In another study, Hua et al. identified a positive correlation between the cytotoxicity of different e-liquids and the total number and total concentration of flavor chemicals [67].

Flavoring chemicals also affect the formation of free radicals. Bitzer et al. found that compounds like non-phenolic terpenes (linalool, dipentene, citral) contribute to a high level of free radical production, probably due to their autooxidation process during which hydroperoxides form. These hydroperoxides can rapidly degrade into allylaxyl and carbon-centered radicals. Ethyl maltol and maltol also promote the generation of radicals, by interaction with iron and copper. On the other hand, in the same study, some flavors inhibited the formation of free radicals. The best results were obtained for ethyl vanillin [66]. 
Table 1. The toxic effects of flavoring ingredients in e-liquids.

\begin{tabular}{ccc}
\hline Flavors & $\begin{array}{c}\text { Chemical Compounds } \\
\text { Found in Flavoring Agents }\end{array}$ & Toxic Potential \\
\hline Mint & Menthol & $\begin{array}{c}\text { Cytotoxic, oxidative, inflammatory, loss } \\
\text { of epithelial barrier function }\end{array}$ \\
\hline Buttery & Diacetyl & Oxidative, inflammatory, lung toxicity \\
\hline Chocolate & Pyrazine derivatives & Cytotoxic \\
\hline Cherry & Benzaldehyde derivatives & $\begin{array}{c}\text { Oxidative, irritant, protein carbonylation } \\
\text { of extracellular matrix, DNA damage }\end{array}$ \\
\hline Cinnamon & Cinnamaldehyde & $\begin{array}{c}\text { Cytotoxic, oxidative, loss of epithelial } \\
\text { barrier function }\end{array}$ \\
\hline Caramel & Vanillin & $\begin{array}{c}\text { Oxidative, cytotoxic, inflammatory, } \\
\text { irritant }\end{array}$ \\
\hline Maltol & $\begin{array}{c}\text { Oxidative, inflammatory, loss of } \\
\text { epithelial barrier function }\end{array}$ \\
\hline
\end{tabular}

Some flavors present in e-liquids are associated with higher reactive oxygen species production rates, and more severe cytotoxicity and inflammatory responses. Pyrazine derivatives are found in chocolate and roasted nut flavors. The pyrazine moiety can interact with p53 tumor suppressor protein, estrogen receptor, and the endothelial growth factor [27]. The p53 gene inactivation is linked to several types of cancers, and p53 is considered "the guardian of the genome" due to its importance in regulating intracellular functions [68].

Aldehydes, like vanillin or cinnamaldehyde, generate oxidative stress, cause protein carbonylation of extracellular matrix, and promote DNA damage responses. As a result, dysregulated repair and impaired wound healing will occur [27,42]. DNA damage appears due to the high reactivity of aldehydes, that bind covalently to macromolecules (DNA and proteins) and cause DNA adducts. A positive correlation between high DNA adduct levels in target organs and elevated cancer risk was observed [43].

Furan derivatives (found in sweet and fruity flavors) caused damage to the nasal mucosa, while furfural derivatives exhibited tumorigenic activity in mice [27].

\subsection{Tobacco-Specific Nitrosamines}

Tobacco-specific nitrosamines (TSNAs) are considered important risk agents in the induction of smoking-related cancers of the lungs, pancreas, esophagus, and oral cavity. NNK (4-(methylnitrosamino)-1-(3-pyridyl)-1-butanone) and NNN (N'-nitrosonornicotine) are included in Group 1 of carcinogens to humans by the World Health Organization (WHO) International Agency for Research on Cancer (IARC) [69].

Tobacco-specific nitrosamines (Figure 6) are procarcinogens and require metabolization and activation. A major metabolic pathway is TSNAs $\alpha$-hydroxylation, several CYP isoforms being involved. The malignant transformations caused by TSNAs are mainly due to the formation of adducts with DNA $[70,71]$. Furthermore, TSNAs are also involved in the migration and invasion of cancer cells, promoting metastasis. A study performed on lung cancer cells revealed that NNK induced phosphorylation and activation of $\mu$ - and $\mathrm{m}$-calpain via ERK1/2. Calpains are matrix-degrading enzymes and have a key role in cancer cells dissemination [72,73].

NNK and NNN, similar to nicotine, have the ability to activate nicotinic acetylcholine receptors (nAChRs), which plays an important role in cancer initiation, but also in chemoresistance [60]. 


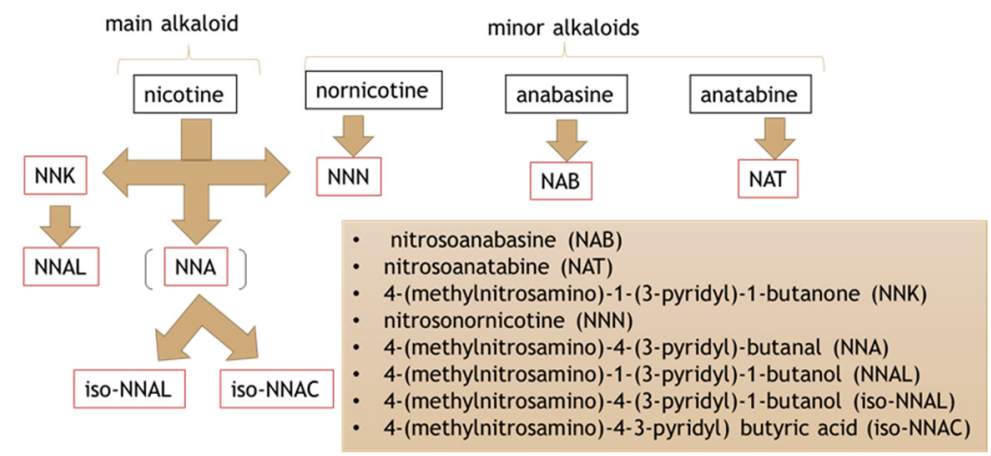

Figure 6. Formation of tobacco-specific nitrosamines.

Kim and Shin analyzed 105 e-liquids, produced by 11 companies, and they quantified tobacco-specific nitrosamines using an LC-MS/MS method. The mean concentrations obtained are presented in Table 2 [74].

Table 2. The levels of TSNAs in 105 replacement liquids of E-cigarettes using LC-MS method (Kim and Shin, 2013).

\begin{tabular}{cc}
\hline Compound & Mean Concentration $(\mu \mathrm{g} / \mathrm{L}) \pm$ SD \\
\hline NNN & $4.06 \pm 9.34$ \\
NNK & $1.71 \pm 1.69$ \\
NAT & $6.36 \pm 12.52$ \\
NAB & $0.90 \pm 1.72$ \\
Total TSNAs & $12.99 \pm 18.23$ \\
\hline
\end{tabular}

Goniewicz et al. analyzed the tobacco nitrosamines in the vapors generated from 12 brands of e-cigarettes and determined the concentrations of NNK and NNN per ecigarette (150 puffs). The values they found were between $0.8 \mathrm{ng}$ and $4.3 \mathrm{ng}$ for NNK and between $1.1 \mathrm{ng}$ and $28.3 \mathrm{ng}$ for NNN) [75].

In another study, Lee et al. analyzed 6 samples of e-liquids, and the concentration of TSNAs in liquid and aerosol samples was measured as below the detection limit [76].

The conclusion of all these studies seems to be that TSNAs exist in a minimum amount in EC liquids, and the carcinogenic risk associated with the presence of TSNAs is low. However, their presence should not be completely ignored, because median levels of $0.47 \mathrm{pg} / \mathrm{mL}$ of NNAL (range: $0.125-3.2 \mathrm{pg} / \mathrm{mL}$ ) were found in the urine of participants who were passively exposed to e-cigarettes. Although the levels are very low, it is difficult to quantify the risks, because there is no safe level of exposure. Additionally, the risks are closely related to the intensity and duration of exposure [77].

\subsection{Heavy Metals}

The International Agency for Research on Cancer (IARC) has classified cadmium (Cd), nickel (Ni), and chromium (in its hexavalent-oxidation state) as carcinogens to humans (Group 1), while inorganic lead $(\mathrm{Pb})$ is classified as a probable carcinogen (Group 2A). Electronic cigarettes can represent a source of toxic and carcinogenic metals. Hess et al. used inductively coupled plasma mass spectrometry to assess toxic metals (cadmium, chromium, lead, manganese, and nickel) concentrations in e-liquid samples [78].

In another study, $\mathrm{Na}$ et al. analyzed the potential of heavy metals transfers from the metallic compartments of e-cigarettes into the e-liquids during use. They found that heavy metal contents usually increased after using electronic devices [79].

There are multiple mechanisms by which metals can induce carcinogenesis: genotoxicity, mutagenesis, oxidative stress, epigenetic modifications, competition with essential metal ions and cancer-related signaling pathways. For example, $\mathrm{Cd}$ induces DNA damage by generating ROS and inhibiting DNA repair. Cd also promotes epigenetic changes, 
altering the DNA methylation status. $\mathrm{Cr}(\mathrm{VI})$ also induces genotoxicity and DNA damage. $\mathrm{Ni}$ facilitates carcinogenesis through epigenetic mechanisms, oxidative stress, and DNA damage [80,81].

\section{Nicotine's Influence on Chemotherapy Drug Resistance}

Oral cancers treatment is usually represented by surgery, radiotherapy, chemotherapy, targeted agents, and immunotherapy. Chemotherapy of oral cancers includes several therapeutic agents (Table 3) [82].

Table 3. Chemotherapy agents used in oral cancer treatment.

\begin{tabular}{|c|c|c|}
\hline Active Compound & Mechanism of Action & Reference \\
\hline Cisplatin & $\begin{array}{c}\text { Induces apoptosis in cancer cells by crosslinking } \\
\text { with the purine bases on the DNA, causing DNA } \\
\text { damage }\end{array}$ & {$[83,84]$} \\
\hline Carboplatin & $\begin{array}{c}\text { Similar mechanism with cisplatin, but with } \\
\text { lower reactivity and slower DNA } \\
\text { binding kinetics }\end{array}$ & [83] \\
\hline Paclitaxel & $\begin{array}{c}\text { Binds to } \beta \text {-subunit of the tubulin protein of the } \\
\text { microtubules, promotes the assembly of tubulin } \\
\text { into microtubules and prevents the dissociation } \\
\text { of microtubules, blocking cell cycle progression, } \\
\text { preventing mitosis, and inhibiting cancer } \\
\text { cells growth }\end{array}$ & [85] \\
\hline Docetaxel & $\begin{array}{l}\text { Similar mechanism to paclitaxel-binds to } \\
\beta \text {-tubulin, and it inhibits the proper assembly of } \\
\text { microtubules into the mitotic spindle, arresting } \\
\text { the cell cycling during } \mathrm{G} 2 / \mathrm{M}\end{array}$ & [86] \\
\hline 5-flurouracil & $\begin{array}{l}\text { Pyrimidine antagonist-antimetabolite with a } \\
\text { similar structure to naturally occurring } \\
\text { compounds that are required for the viability } \\
\text { and division of a cell; it inhibits the replication or } \\
\text { the repair of DNA }\end{array}$ & {$[87,88]$} \\
\hline Hydroxyurea & $\begin{array}{c}\text { Inhibits ribonucleotide reductase and blocks the } \\
\text { formation of nucleotides needed for DNA } \\
\text { synthesis and repair }\end{array}$ & [87] \\
\hline Methotrexate & $\begin{array}{l}\text { Folate antagonist; it inhibits dihydrofolate } \\
\text { reductase, affecting the de novo synthesis of } \\
\text { purines used in DNA replication }\end{array}$ & {$[87,89]$} \\
\hline Capecitabine & Similar mechanism with 5-fluorouracil & [87] \\
\hline
\end{tabular}

Doctors observed that smoking cancer patients have lower chemotherapy response rates, mainly due to nicotine's ability to inhibit apoptosis and induce chemoresistance in cancer cells. Nicotine inhibited the apoptotic effect of cisplastin, vinblastine, paclitaxel, and doxorubicin $[60,90]$.

$\mathrm{Xu}$ et al. assess the impact of nicotine on cisplatin-induced apoptosis in human oral cancer cells and observed that nicotine exposure inhibited apoptosis induced by cisplatin. They demonstrated that survivin and the Akt pathway play an important role in this process [91].

Chernyavsky et al. investigated the effects of nicotine on oral and lung cancer cells and demonstrated that activated cell membrane-localized nAchRs form complexes with EGFR and VEGFR, while activated mitochondrial-nAchRs form complexes with phosphatidylinositol 3-kinases (PI3K) and Src (proto-oncogene tyrosine-protein kinase). The results of these interactions are increased cell proliferation, upregulated expression of cyclin D1 (a protein required for progression through the G1 phase of the cell cycle,) activation of 
ERK1/2 (extracellular signal-regulated kinases that act in a signaling cascade regulating proliferation, differentiation, and cell cycle progression), but also the inhibition of the apoptogen-induced opening of $\mathrm{MPTP}$ (the mitochondrial permeability transition pore). The inhibition of apoptogen-induced opening of mPTP can represent a mechanism that explains nicotine's protection of cancer cells from chemotherapy-induced apoptosis. mPTP opening can cause apoptosis due to the massive swelling of mitochondria, which leads to membrane rupture and release of components [57].

In another study, Cucina et al. investigated the activation of survival pathways in colon cancer cells exposed to nicotine. The results revealed the involvement of $\alpha 7$-AChRs in cell growth and apoptosis. Additionally, nicotine increased the expressions of PI3K, P-Akt/Akt, PKC, ERK1/2, survivin, and P-Bcl2 [92].

$\alpha 7-A C h R s$ were also involved in cancer cell survival and cisplatin resistance [62], and the involvement of $\alpha 7$ subunit of $\mathrm{nAChR}$ can be used to increase the effect of chemotherapy because adding $\alpha 7$ antagonists to the treatment of cancer patients could improve the anti-proliferative effect $[57,60]$.

To sum up, nicotine's antiapoptotic potential can be explained through several mechanisms (Figure 7), like the activation of the PI3K/Akt pathway, the overexpression of surviving, the induction of $\mathrm{Bcl} 2$ phosphorylation (as a consequence of PKC and ERK1/2 activation) [92]. $\mathrm{Bcl} 2$ is an anti-apoptotic protein, and simultaneous treatment with cisplatin and nicotine determined the activation of $\mathrm{Bcl} 2$ and induced resistance to cisplatin in cancer cells $[57,62]$.

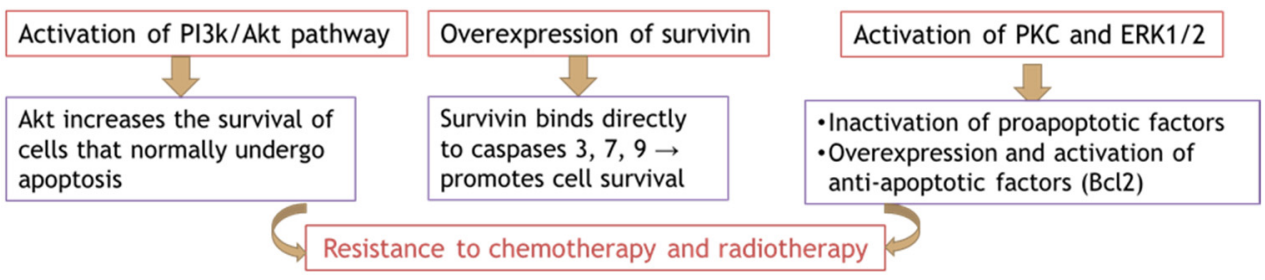

Figure 7. Nicotine's antiapoptotic activity.

Another direction in the therapy of oral cancer patients is antitumor immunotherapy. Immunotherapy focuses on the stimulation of the specific activity of the immune system to attack abnormal cells and destroy them. In some cancerous processes, the activity of immune T-cells, and cytokine production are inhibited via programmed cell death protein-1/programmed cell death protein ligand-1 (PD-1/PD-L1) pathway. To counteract this phenomenon, monoclonal antibodies that bind to the PD-1 receptor and block its interaction with PD-ligands were obtained and introduced in cancer therapy (eq. pembrolizumab). Another class of immunotherapy agents is monoclonal antibodies targeting EGFR - epidermal growth factor receptor (eq. cetuximab, panitumumab) [93].

The immunosuppressive and anti-inflammatory potential of nicotine $[94,95]$ can affect the activity of immune cells, and reduce the quantity of inflammatory cytokines, vital for immunotherapy success [50]. However, an increased PD-L1 expression is associated with nicotine-product consumption, and some literature meta-analysis showed that smokers could benefit more from anti-PD-1/PD-L1 therapy than non-smokers [96-99].

The issue of whether nicotine or other tobacco products can be used as potential immunotherapy sensitizers is still controversial. More studies regarding nicotine's influence on immunotherapy efficiency in oral cancer are needed. Furthermore, it is difficult to draw conclusions regarding the influence of vaping on cancer immunotherapy because the investigations in this direction were not performed for electronic smoking devices, and cigarette smoke has a much more complex composition than e-vapors.

\section{Conclusions}

This research subject (the health impact of vaping) is of great interest due to the popularity of this habit. These products are called Modified Risk Tobacco Products [100] 
and promise to offer a less harmful alternative for smokers. There is scientific evidence supporting the benefits of switching from conventional cigarettes to electronic nicotine delivery devices, including in the oral health area, but it is very dangerous to promote electronic cigarettes as low-risk products, especially among young people or pregnant women who are trying to quit smoking.

The oral tissues are extremely exposed to the potentially harmful effects of electronic cigarettes, and although many signs of progress have been made in the last few years, there are still research gaps regarding the effects of short-term and long-term exposure to e-vapors. However, the evidence gathered so far clearly indicates that vaping affects the periodontal ligament and fibroblasts and can be linked to serious health issues-like periodontitis and oral cancer. It is important to understand the mechanisms behind the toxicity of electronic cigarettes and how different variables (eq. the chemical composition of e-liquids) can influence the outcome. The different compositions of the tens of thousands of e-liquids can affect the experimental results and it is also difficult to quantify e-cigarette exposure.

Future research should focus on robust-designed studies, especially in vivo studies, in order to obtain conclusive results and strong evidence for the impact of e-cigarettes on periodontal and oral cancer initiation and progression. Quality scientific information is vital for the introduction of standardized regulations of these products. Additionally, it is essential to determine to what extend vaping can influence the success of chemotherapy and in cancer patients.

Author Contributions: Conceptualization, A.J., I.M.; methodology, A.G., D.D.P., O.D.A.; investigation, A.J., I.M., I.-C.C., C.S., B.P.; writing-review and editing, A.J., I.M., L.A., O.D.A., S.T.; supervision, A.G., D.D.P., L.A.; project administration, A.J., I.M.; funding acquisition, A.J. All authors have read and agreed to the published version of the manuscript.

Funding: This research was funded by GRIGORE T. POPA. UNIVERSITY OF MEDICINE AND PHARMACY IAȘI, Romania, grant number. 4717/25.02.2021.

Institutional Review Board Statement: Not applicable.

Informed Consent Statement: Not applicable.

Data Availability Statement: Not applicable.

Conflicts of Interest: The authors declare no conflict of interest.

\section{References}

1. Kumar, P.; Geisinger, M.; DeLong, H.R.; Lipman, R.D.; Araujo, M.W.B. Living under a cloud: Electronic cigarettes and the dental patient. J. Am. Dent. Assoc. 2020, 151, 155-158. [CrossRef]

2. Sundar, I.K.; Javed, F.; Romanos, G.E.; Rahman, I. E-cigarettes and flavorings induce inflammatory and pro-senescence responses in oral epithelial cells and periodontal fibroblasts. Oncotarget 2016, 7, 77196-77204. [CrossRef]

3. Kaur, G.; Pinkston, R.; Mclemore, B.; Dorsey, W.C.; Batra, S. Immunological and toxicological risk assessment of e-cigarettes. Eur. Respir. Rev. 2018, 27, 170119. [CrossRef]

4. Holliday, R.; Chaffee, B.W.; Jakubovics, N.S.; Kist, R.; Preshaw, P.M. Electronic Cigarettes and Oral Health. J. Dent. Res. 2021, 100, 906-913. [CrossRef] [PubMed]

5. Huilgol, P.; Bhatt, S.P.; Biligowda, N.; Wright, N.C.; Wells, J.M. Association of e-cigarette use with oral health: A population-based cross-sectional questionnaire study. J. Public Health 2019, 41, 354-361. [CrossRef]

6. Rouabhia, M. Impact of Electronic Cigarettes on Oral Health: A Review. J. Can. Dent. Assoc. 2020, 86, k7. [PubMed]

7. Wadia, R.; Booth, V.; Yap, H.F.; Moyes, D.L. A pilot study of the gingival response when smokers switch from smoking to vaping. Br. Dent. J. 2016, 221, 722-726. [CrossRef] [PubMed]

8. Mokeem, S.A.; Alasqah, M.N.; Michelogiannakis, D.; Al-Kheraif, A.A.; Romanos, G.E.; Javed, F. Clinical and radiographic periodontal status and whole salivary cotinine, IL-1 $\beta$ and IL-6 levels in cigarette- and waterpipe-smokers and E-cig users. Environ. Toxicol. Pharmacol. 2018, 61, 38-43. [CrossRef] [PubMed]

9. Javed, F.; Abduljabbar, T.; Vohra, F.; Malmstrom, H.; Rahman, I.; Romanos, G.E. Comparison of Periodontal Parameters and Self-Perceived Oral Symptoms Among Cigarette Smokers, Individuals Vaping Electronic Cigarettes, and Never-Smokers. J. Periodontol. 2017, 88, 1059-1065. [CrossRef] 
10. Ralho, A.; Coelho, A.; Ribeiro, M.; Paula, A.; Amaro, I.; Sousa, J.; Marto, C.; Ferreira, M.; Carrilho, E. Effects of Electronic Cigarettes on Oral Cavity: A Systematic Review. J. Evid. Based Dent. Pract 2019, 19, 101318. [CrossRef]

11. Sung, H.; Ferlay, J.; Siegel, R.L.; Laversanne, M.; Soerjomataram, I.; Jemal, A.; Bray, F. Global Cancer Statistics 2020: GLOBOCAN Estimates of Incidence and Mortality Worldwide for 36 Cancers in 185 Countries. CA Cancer J. Clin. 2021, 71, 209-249. [CrossRef] [PubMed]

12. Allam, E.; Zhang, W.; Al-Shibani, N.; Sun, J.; Labban, N.; Song, F.; Windsor, L.J. Effects of cigarette smoke condensate on oral squamous cell carcinoma cells. Arch. Oral Biol. 2011, 56, 1154-1161. [CrossRef] [PubMed]

13. Katarkar, A.; Patel, L.; Mukherjee, S.; Ray, J.G.; Haldar, P.K.; Chaudhuri, K. Association of oral tumor suppressor gene deleted in oral cancer-1 (DOC-1) in progression of oral precancer to cancer. Oral Sci. Int. 2015, 12, 15-21. [CrossRef]

14. Yao, Q.W.; Zhou, D.S.; Peng, H.J.; Ji, P.; Liu, D.S. Association of periodontal disease with oral cancer:a meta-analysis. Tumour. Biol. 2014, 35, 7073-7077. [CrossRef] [PubMed]

15. Zeng, X.T.; Deng, A.P.; Li, C.; Xia, L.Y.; Niu, Y.M.; Leng, W.D. Periodontal disease and risk of head and neck cancer: A meta-analysis of observational studies. PLoS ONE 2013, 8, e79017. [CrossRef]

16. Lu, M.; Xuan, S.; Wang, Z. Oral microbiota: A new view of body health. Food Sci. Hum. Wellness 2019, 8, 8-15. [CrossRef]

17. Almeida-da-Silva, C.L.C.; Matshik Dakafay, H.; O’Brien, K.; Montierth, D.; Xiao, N.; Ojcius, D.M. Effects of electronic cigarette aerosol exposure on oral and systemic health. Biomed. J. 2021, 44, 252-259. [CrossRef]

18. Radaic, A.; Kapila, Y.L. The oralome and its dysbiosis: New insights into oral microbiome-host interactions. Comput. Struct. Biotechnol. J. 2021, 19, 1335-1360. [CrossRef]

19. Pushalkar, S.; Paul, B.; Li, Q.; Yang, J.; Vasconcelos, R.; Makwana, S.; González, J.M.; Shah, S.; Xie, C.; Janal, M.N.; et al. Electronic Cigarette Aerosol Modulates the Oral Microbiome and Increases Risk of Infection. iScience 2020, 23, 100884. [CrossRef]

20. Ganesan, S.M.; Dabdoub, S.M.; Nagaraja, H.N.; Scott, M.L.; Pamulapati, S.; Berman, M.L.; Shields, P.G.; Wewers, M.E.; Kumar, P.S Adverse effects of electronic cigarettes on the disease-naive oral microbiome. Sci. Adv. 2020, 6, eaaz0108. [CrossRef]

21. Javed, F.; Warnakulasuriya, S. Is there a relationship between periodontal disease and oral cancer? A systematic review of currently available evidence. Crit. Rev. Oncol. Hematol. 2016, 97, 197-205. [CrossRef] [PubMed]

22. Sahingur, S.E.; Yeudall, W.A. Chemokine function in periodontal disease and oral cavity cancer. Front. Immunol. 2015, 6, 214 [CrossRef] [PubMed]

23. Tommasi, S.; Caliri, A.W.; Caceres, A.; Moreno, D.E.; Li, M.; Chen, Y.; Siegmund, K.D.; Besaratinia, A. Deregulation of Biologically Significant Genes and Associated Molecular Pathways in the Oral Epithelium of Electronic Cigarette Users. Int. J. Mol. Sci. 2019, 20, 738. [CrossRef] [PubMed]

24. Vairaktaris, E.; Yapijakis, C.; Serefoglou, Z.; Derka, S.; Vassiliou, S.; Nkenke, E.; Vylliotis, A.; Wiltfang, J.; Avgoustidis, D.; Critselis, E.; et al. The interleukin-8 (-251A/T) polymorphism is associated with increased risk for oral squamous cell carcinoma. Eur. J. Surg. Oncol. 2007, 33, 504-507. [CrossRef] [PubMed]

25. Cordero, O.J.; Varela-Calviño, R. Oral hygiene might prevent cancer. Heliyon 2018, 4, e00879. [CrossRef] [PubMed]

26. Merecz-Sadowska, A.; Sitarek, P.; Zielinska-Blizniewska, H.; Malinowska, K.; Zajdel, K.; Zakonnik, L.; Zajdel, R. A Summary of In Vitro and In Vivo Studies Evaluating the Impact of E-Cigarette Exposure on Living Organisms and the Environment. Int. J. Mol. Sci. 2020, 21, 652. [CrossRef]

27. Lucas, J.H.; Muthumalage, T.; Wang, Q.; Friedman, M.R.; Friedman, A.E.; Rahman, I. E-Liquid Containing a Mixture of Coconut, Vanilla, and Cookie Flavors Causes Cellular Senescence and Dysregulated Repair in Pulmonary Fibroblasts: Implications on Premature Aging. Front. Physiol. 2020, 11, 924. [CrossRef]

28. Munther, S. The effects of cigarette smoking and exercise on total salivary antioxidant activity. Saudi Dent. J. 2019, 31, 31-38. [CrossRef]

29. Dalle-Donne, I.; Garavaglia, M.L.; Colombo, G.; Astori, E.; Lionetti, M.C.; La Porta, C.A.M.; Santucci, A.; Rossi, R.; Giustarini, D.; Milzani, A. Cigarette smoke and glutathione: Focus on in vitro cell models. Toxicol. In Vitro 2020, 65, 104818. [CrossRef]

30. Lerner, C.A.; Sundar, I.K.; Watson, R.M.; Elder, A.; Jones, R.; Done, D.; Kurtzman, R.; Ossip, D.J.; Robinson, R.; McIntosh, S.; et al . Environmental health hazards of e-cigarettes and their components: Oxidants and copper in e-cigarette aerosols. Environ. Pollut. 2015, 198, 100-107. [CrossRef]

31. Lerner, C.A.; Rutagarama, P.; Ahmad, T.; Sundar, I.K.; Elder, A.; Rahman, I. Electronic cigarette aerosols and copper nanoparticles induce mitochondrial stress and promote DNA fragmentation in lung fibroblasts. Biochem. Biophys. Res. Commun. 2016, 477, 620-625. [CrossRef]

32. Isik Andrikopoulos, G.; Zagoriti, Z.; Topouzis, S.; Poulas, K. Oxidative stress induced by electronic nicotine delivery systems (ENDS): Focus on respiratory system. Curr. Opin. Toxicol. 2019, 13, 81-89. [CrossRef]

33. Isik Andrikopoulos, G.; Farsalinos, K.; Poulas, K. Electronic Nicotine Delivery Systems (ENDS) and Their Relevance in Oral Health. Toxics 2019, 7, 61. [CrossRef] [PubMed]

34. Faridoun, A. A Comparison of the Levels of Salivary Biomarkers between Conventional Smokers and Electronic Cigarette Users (A Pilot Study). Master's Thesis, Biomedical Sciences-Dental School University of Maryland, Baltimore, MD, USA, 2019.

35. Peng, H.Y.; Hsiao, J.R.; Chou, S.T.; Hsu, Y.M.; Wu, G.H.; Shieh, Y.S.; Shiah, S.G. MiR-944/CISH mediated inflammation via STAT3 is involved in oral cancer malignance by cigarette smoking. Neoplasia 2020, 22, 554-565. [CrossRef] [PubMed] 
36. Alanazi, H.; Park, H.J.; Chakir, J.; Semlali, A.; Rouabhia, M. Comparative study of the effects of cigarette smoke and electronic cigarettes on human gingival fibroblast proliferation, migration and apoptosis. Food Chem. Toxicol. 2018, 118, 390-398. [CrossRef] [PubMed]

37. Willershausen, I.; Wolf, T.; Weyer, V.; Sader, R.; Ghanaati, S.; Willershausen, B. Influence of E-smoking liquids on human periodontal ligament fibroblasts. Head Face Med. 2014, 10, 39. [CrossRef] [PubMed]

38. Yu, V.; Rahimy, M.; Korrapati, A.; Xuan, Y.; Zou, A.E.; Krishnan, A.R.; Tsui, T.; Aguilera, J.A.; Advani, S.; Crotty Alexander, L.E.; et al. Electronic cigarettes induce DNA strand breaks and cell death independently of nicotine in cell lines. Oral Oncol. 2016, 52, 58-65. [CrossRef]

39. Schwarzmeier, L.Â.T.; da Cruz, B.S.; Ferreira, C.C.P.; Carvalho, B.F.D.C.; Alves, M.G.O.; Lima Carta, C.F.; Scholz, J.R.; Almeida, J.D. E-cig might cause cell damage of oral mucosa. Oral Surg. Oral Med. Oral Pathol. Oral Radiol. 2021, 131, 435-443. [CrossRef]

40. Argentin, G.; Cicchetti, R. Genotoxic and antiapoptotic effect of nicotine on human gingival fibroblasts. Toxicol. Sci. 2004, 79, 75-81. [CrossRef]

41. Ginzkey, C.; Steussloff, G.; Koehler, C.; Burghartz, M.; Scherzed, A.; Hackenberg, S.; Hagen, R.; Kleinsasser, N.H. Nicotine derived genotoxic effects in human primary parotid gland cells as assessed in vitro by comet assay, cytokinesis-block micronucleus test and chromosome aberrations test. Toxicol. In Vitro 2014, 28, 838-846. [CrossRef]

42. Javed, F.; Kellesarian, S.V.; Sundar, I.K.; Romanos, G.E.; Rahman, I. Recent updates on electronic cigarette aerosol and inhaled nicotine effects on periodontal and pulmonary tissues. Oral Dis. 2017, 23, 1052-1057. [CrossRef] [PubMed]

43. Kang, J.C.; Valerio, L.G., Jr. Investigating DNA adduct formation by flavor chemicals and tobacco byproducts in electronic nicotine delivery system (ENDS) using in silico approaches. Toxicol. Appl. Pharmacol. 2020, 398, 115026. [CrossRef] [PubMed]

44. Fukuda, M.; Kusama, K.; Sakashita, H. Molecular insights into the proliferation and progression mechanisms of the oral cancer: Strategies for the effective and personalized therapy. Jpn. Dent. Sci. Rev. 2012, 48, 23-41. [CrossRef]

45. Vo, J.N.; Cieslik, M.; Zhang, Y.; Shukla, S.; Xiao, L.; Zhang, Y.; Wu, Y.M.; Dhanasekaran, S.M.; Engelke, C.G.; Cao, X.; et al. The Landscape of Circular RNA in Cancer. Cell 2019, 176, 869-881.e13. [CrossRef] [PubMed]

46. Su, W.; Shen, Y.; Wang, Y.; Wang, F.; Hong, X.; Chen, Y.; Lin, Y.; Yang, H. circPHIP promotes oral squamous cell carcinoma progression by sponging miR-142-5p and regulating PHIP and ACTN4 expression. Mol. Ther. Nucleic Acids 2020, 23, 185-199. [CrossRef]

47. Singh, K.P.; Maremanda, K.P.; Li, D.; Rahman, I. Exosomal microRNAs are novel circulating biomarkers in cigarette, waterpipe smokers, E-cigarette users and dual smokers. BMC Med. Genom. 2020, 13, 128. [CrossRef]

48. Solleti, S.K.; Bhattacharya, S.; Ahmad, A.; Wang, Q.; Mereness, J.; Rangasamy, T.; Mariani, T.J. MicroRNA expression profiling defines the impact of electronic cigarettes on human airway epithelial cells. Sci. Rep. 2017, 7, 1081. [CrossRef]

49. Sewer, A.; Zanetti, F.; Iskandar, A.R.; Guedj, E.; Dulize, R.; Peric, D.; Bornand, D.; Mathis, C.; Martin, F.; Ivanov, N.V.; et al. A meta-analysis of microRNAs expressed in human aerodigestive epithelial cultures and their role as potential biomarkers of exposure response to nicotine-containing products. Toxicol. Rep. 2020, 7, 1282-1295. [CrossRef]

50. Xie, Z.; Rahman, I.; Goniewicz, M.L.; Li, D. Perspectives on Epigenetics Alterations Associated with Smoking and Vaping. Function 2021, 2, zqab022. [CrossRef]

51. Armendáriz-Castillo, I.; Guerrero, S.; Vera-Guapi, A.; Cevallos-Vilatuña, T.; García-Cárdenas, J.M.; Guevara-Ramírez, P.; LópezCortés, A.; Pérez-Villa, A.; Yumiceba, V.; Zambrano, A.K.; et al. Genotoxic and Carcinogenic Potential of Compounds Associated with Electronic Cigarettes: A Systematic Review. BioMed Res. Int. 2019, 2019, 1386710. [CrossRef]

52. Sancilio, S.; Gallorini, M.; Cataldi, A.; Sancillo, L.; Rana, R.A.; di Giacomo, V. Modifications in Human Oral Fibroblast Ultrastructure, Collagen Production, and Lysosomal Compartment in Response to Electronic Cigarette Fluids. J. Periodontol. 2017, 88, 673-680. [CrossRef]

53. Heeschen, C.; Jang, J.J.; Weis, M.; Pathak, A.; Kaji, S.; Hu, R.S.; Tsao, P.S.; Johnson, F.L.; Cooke, J.P. Nicotine stimulates angiogenesis and promotes tumor growth and atherosclerosis. Nat. Med. 2001, 7, 833-839. [CrossRef]

54. Xin, M.; Deng, X. Nicotine inactivation of the proapoptotic function of Bax through phosphorylation. J. Biol. Chem. 2005, 280, 10781-10789. [CrossRef]

55. Fortier, A.M.; Asselin, E.; Cadrin, M. Functional specificity of Akt isoforms in cancer progression. Biomol. Concepts 2011, 2, 1-11. [CrossRef]

56. Chen, R.-J.; Ho, Y.-S.; Wu, C.-H.; Wang, Y.-J. Molecular Mechanisms of Nicotine-induced Bladder Cancer. J. Exp. Clin. Med. 2011, 3, 252-256. [CrossRef]

57. Chernyavsky, A.I.; Shchepotin, I.B.; Grando, S.A. Mechanisms of growth-promoting and tumor-protecting effects of epithelial nicotinic acetylcholine receptors. Int. Immunopharmacol. 2015, 29, 36-44. [CrossRef]

58. Gotti, C.; Clementi, F. Neuronal nicotinic receptors: From structure to pathology. Prog. Neurobiol. 2004, 74, 363-396. [CrossRef] [PubMed]

59. Egleton, R.D.; Brown, K.C.; Dasgupta, P. Nicotinic acetylcholine receptors in cancer: Multiple roles in proliferation and inhibition of apoptosis. Trends Pharmacol. Sci. 2008, 29, 151-158. [CrossRef] [PubMed]

60. Afrashteh Nour, M.; Hajiasgharzadeh, K.; Kheradmand, F.; Asadzadeh, Z.; Bolandi, N.; Baradaran, B. Nicotinic acetylcholine receptors in chemotherapeutic drugs resistance: An emerging targeting candidate. Life Sci. 2021, 278, 119557. [CrossRef] [PubMed] 
61. Wisniewski, D.J.; Ma, T.; Schneider, A. Nicotine induces oral dysplastic keratinocyte migration via fatty acid synthase-dependent epidermal growth factor receptor activation. Exp. Cell Res. 2018, 370, 343-352. [CrossRef]

62. Hsu, C.C.; Tsai, K.Y.; Su, Y.F.; Chien, C.Y.; Chen, Y.C.; Wu, Y.C.; Liu, S.Y.; Shieh, Y.S. $\alpha 7-$ Nicotine acetylcholine receptor mediated nicotine induced cell survival and cisplatin resistance in oral cancer. Arch. Oral Biol. 2020, 111, 104653. [CrossRef] [PubMed]

63. Yu, C.C.; Chang, Y.C. Enhancement of cancer stem-like and epithelial-mesenchymal transdifferentiation property in oral epithelial cells with long-term nicotine exposure: Reversal by targeting SNAIL. Toxicol. Appl. Pharmacol. 2013, 266, 459-469. [CrossRef] [PubMed]

64. Bitzer, Z.T.; Goel, R.; Reilly, S.M.; Foulds, J.; Muscat, J.; Elias, R.J.; Richie, J.P., Jr. Effects of Solvent and Temperature on Free Radical Formation in Electronic Cigarette Aerosols. Chem. Res. Toxicol. 2018, 31, 4-12. [CrossRef] [PubMed]

65. Kaur, G.; Muthumalage, T.; Rahman, I. Mechanisms of toxicity and biomarkers of flavoring and flavor enhancing chemicals in emerging tobacco and non-tobacco products. Toxicol. Lett. 2018, 288, 143-155. [CrossRef] [PubMed]

66. Bitzer, Z.T.; Goel, R.; Reilly, S.M.; Elias, R.J.; Silakov, A.; Foulds, J.; Muscat, J.; Richie, J.P., Jr. Effect of flavoring chemicals on free radical formation in electronic cigarette aerosols. Free Radic. Biol. Med. 2018, 120, 72-79. [CrossRef]

67. Hua, M.; Omaiye, E.E.; Luo, W.; McWhirter, K.J.; Pankow, J.F.; Talbot, P. Identification of Cytotoxic Flavor Chemicals in Top-Selling Electronic Cigarette Refill Fluids. Sci. Rep. 2019, 9, 2782. [CrossRef]

68. Aldakheel, F.M.; Abuderman, A.A.; Alali, B.H.; Mateen, A.; Alduraywish, S.A.; Jamil, K.; Alqahtani, M.S.; Syed, R. Smoking and P53 polymorphism association with chromosomal aberration in lung cancer. J. King Saud Univ. Sci. 2021, 33, 101533. [CrossRef]

69. Ishizaki, A.; Kataoka, H. A sensitive method for the determination of tobacco-specific nitrosamines in mainstream and sidestream smokes of combustion cigarettes and heated tobacco products by online in-tube solid-phase microextraction coupled with liquid chromatography-tandem mass spectrometry. Anal. Chim. Acta 2019, 1075, 98-105. [CrossRef]

70. Konstantinou, E.; Fotopoulou, F.; Drosos, A.; Dimakopoulou, N.; Zagoriti, Z.; Niarchos, A.; Makrynioti, D.; Kouretas, D.; Farsalinos, K.; Lagoumintzis, G.; et al. Tobacco-specific nitrosamines: A literature review. Food Chem. Toxicol. 2018, 118, 198-203. [CrossRef]

71. Yalcin, E.; de la Monte, S. Tobacco nitrosamines as culprits in disease: Mechanisms reviewed. J. Physiol. Biochem. 2016, 72, 107-120. [CrossRef]

72. Improgo, M.R.; Tapper, A.R.; Gardner, P.D. Nicotinic acetylcholine receptor-mediated mechanisms in lung cancer. Biochem. Pharmacol. 2011, 82, 1015-1021. [CrossRef]

73. Xu, L.; Deng, X. Tobacco-specific nitrosamine 4-(methylnitrosamino)-1-(3-pyridyl)-1-butanone induces phosphorylation of muand m-calpain in association with increased secretion, cell migration, and invasion. J. Biol. Chem. 2004, 279, 53683-53690. [CrossRef]

74. Kim, H.J.; Shin, H.S. Determination of tobacco-specific nitrosamines in replacement liquids of electronic cigarettes by liquid chromatography-tandem mass spectrometry. J. Chromatogr. A 2013, 1291, 48-55. [CrossRef]

75. Goniewicz, M.L.; Knysak, J.; Gawron, M.; Kosmider, L.; Sobczak, A.; Kurek, J.; Prokopowicz, A.; Jablonska-Czapla, M.; RosikDulewska, C.; Havel, C.; et al. Levels of selected carcinogens and toxicants in vapour from electronic cigarettes. Tob. Control 2014, 23, 133-139. [CrossRef]

76. Lee, Y.S.; Kim, K.H.; Lee, S.S.; Brown, R.J.C.; Jo, S.H. Analytical Method for Measurement of Tobacco-Specific Nitrosamines in E-Cigarette Liquid and Aerosol. Appl. Sci. 2018, 8, 2699. [CrossRef]

77. Martínez-Sánchez, J.M.; Ballbè, M.; Pérez-Ortuño, R.; Fu, M.; Sureda, X.; Pascual, J.A.; Peruga, A.; Fernández, E. Secondhand exposure to aerosol from electronic cigarettes: Pilot study of assessment of tobacco-specific nitrosamine (NNAL) in urine. Gac. Sanit. 2019, 33, 575-578. [CrossRef] [PubMed]

78. Hess, C.A.; Olmedo, P.; Navas-Acien, A.; Goessler, W.; Cohen, J.E.; Rule, A.M. E-cigarettes as a source of toxic and potentially carcinogenic metals. Environ. Res. 2017, 152, 221-225. [CrossRef] [PubMed]

79. Na, C.J.; Jo, S.H.; Kim, K.H.; Sohn, J.R.; Son, Y.S. The transfer characteristics of heavy metals in electronic cigarette liquid. Environ. Res. 2019, 174, 152-159. [CrossRef] [PubMed]

80. Zhu, Y.; Costa, M. Metals and molecular carcinogenesis. Carcinogenesis 2020, 41, 1161-1172. [CrossRef]

81. Kim, H.S.; Kim, Y.J.; Seo, Y.R. An Overview of Carcinogenic Heavy Metal: Molecular Toxicity Mechanism and Prevention. J. Cancer Prev. 2015, 20, 232-240. [CrossRef]

82. Geiger, J.L.; Adelstein, D.J. Chemotherapy in the definitive management of oral cancers: Where do we stand today? Oral Oncol. 2020, 102, 104584. [CrossRef]

83. Dasari, S.; Tchounwou, P.B. Cisplatin in cancer therapy: Molecular mechanisms of action. Eur. J. Pharmacol. 2014, 740, 364-378. [CrossRef]

84. Ghosh, S. Cisplatin: The first metal based anticancer drug. Bioorg. Chem. 2019, 88, 102925. [CrossRef]

85. Zhu, L.; Chen, L. Progress in research on paclitaxel and tumor immunotherapy. Cell Mol. Biol. Lett. 2019, 24, 40. [CrossRef] [PubMed]

86. Farha, N.G.; Kasi, A. Docetaxel. In StatPearls [Internet]; StatPearls Publishing: Treasure Island, FL, USA, 2021; Available online: https: / / www.ncbi.nlm.nih.gov / books /NBK537242/ (accessed on 15 September 2021).

87. Thirumaran, R.; Prendergast, G.C.; Gilman, P.B. Cytotoxic Chemotherapy in Clinical Treatment of Cancer. In Cancer Immunotherapy: Immune Suppression and Tumor Growth; Prendergast, G.C., Jaffee, E.M., Eds.; Academic Press: San Diego, CA, USA, 2011; pp. 101-116. 
88. Zhang, N.; Yin, Y.; Xu, S.J.; Chen, W.S. 5-Fluorouracil: Mechanisms of resistance and reversal strategies. Molecules 2008, 13, 1551-1569. [CrossRef]

89. Bedoui, Y.; Guillot, X.; Sélambarom, J.; Guiraud, P.; Giry, C.; Jaffar-Bandjee, M.C.; Ralandison, S.; Gasque, P. Methotrexate an Old Drug with New Tricks. Int. J. Mol. Sci. 2019, 20, 5023. [CrossRef] [PubMed]

90. Petros, W.P.; Younis, I.R.; Ford, J.N.; Weed, S.A. Effects of tobacco smoking and nicotine on cancer treatment. Pharmacotherapy 2012, 32, 920-931. [CrossRef]

91. Xu, J.; Huang, H.; Pan, C.; Zhang, B.; Liu, X.; Zhang, L. Nicotine inhibits apoptosis induced by cisplatin in human oral cancer cells. Int. J. Oral Maxillofac. Surg. 2007, 36, 739-744. [CrossRef] [PubMed]

92. Cucina, A.; Dinicola, S.; Coluccia, P.; Proietti, S.; D'Anselmi, F.; Pasqualato, A.; Bizzarri, M. Nicotine stimulates proliferation and inhibits apoptosis in colon cancer cell lines through activation of survival pathways. J. Surg. Res. 2012, 178, 233-241. [CrossRef]

93. Mohan, S.P.; Bhaskaran, M.K.; George, A.L.; Thirutheri, A.; Somasundaran, M.; Pavithran, A. Immunotherapy in Oral Cancer. J. Pharm. Bioallied Sci. 2019, 11 (Suppl. 2), S107-S111. [CrossRef] [PubMed]

94. Piao, W.H.; Campagnolo, D.; Dayao, C.; Lukas, R.J.; Wu, J.; Shi, F.D. Nicotine and inflammatory neurological disorders. Acta Pharmacol. Sin. 2009, 30, 715-722. [CrossRef] [PubMed]

95. Kalra, R.; Singh, S.P.; Pena-Philippides, J.C.; Langley, R.J.; Razani-Boroujerdi, S.; Sopori, M.L. Immunosuppressive and antiinflammatory effects of nicotine administered by patch in an animal model. Clin. Diagn. Lab. Immunol. 2004, 11, 563-568. [CrossRef] [PubMed]

96. Mo, J.; Hu, X.; Gu, L.; Chen, B.; Khadaroo, P.A.; Shen, Z.; Dong, L.; Lv, Y.; Chitumba, M.N.; Liu, J. Smokers or non-smokers: Who benefits more from immune checkpoint inhibitors in treatment of malignancies? An up-to-date meta-analysis. World J. Surg. Oncol. 2020, 18, 15. [CrossRef] [PubMed]

97. Norum, J.; Nieder, C. Tobacco smoking and cessation and PD-L1 inhibitors in non-small cell lung cancer (NSCLC): A review of the literature. ESMO Open 2018, 3, e000406. [CrossRef]

98. Zaleskis, G.; Pasukoniene, V.; Characiejus, D.; Urbonas, V. Do the benefits of being a smoker hint at the existence of PD-1/PD-L1 sensitizers for patients on single-agent immunotherapy? J. Immunother. Cancer 2021, 9, e003191. [CrossRef]

99. Dai, L.; Jin, B.; Liu, T.; Chen, J.; Li, G.; Dang, J. The effect of smoking status on efficacy of immune checkpoint inhibitors in metastatic non-small cell lung cancer: A systematic review and meta-analysis. EClinicalMedicine 2021, 38, 100990. [CrossRef]

100. Zanetti, F.; Titz, B.; Sewer, A.; Lo Sasso, G.; Scotti, E.; Schlage, W.K.; Mathis, C.; Leroy, P.; Majeed, S.; Torres, L.O.; et al. Comparative systems toxicology analysis of cigarette smoke and aerosol from a candidate modified risk tobacco product in organotypic human gingival epithelial cultures: A 3-day repeated exposure study. Food Chem. Toxicol. 2017, 101, 15-35. [CrossRef] 